\title{
Innovative Combined Technology in Metal Treatment
}

\author{
Sergey B. Sidelnikov*, \\ Yuriy V. Gorokhov and Sergey V. Belyaev \\ Siberian Federal University \\ 79 Svobodny, Krasnoyarsk, 660041, Russia
}

The review of the combined technologies of metal treatment is submitted. Particular attention is given to aggregates that combine continuous casting and pressing. The theoretical relationships between the mechanical properties of moldings and the parameters of the continuous casting-pressing process are experimentally verified. The experimental industrial plant combined injection-molding aluminum and a copper alloy is designed. The methods combined rolling-extrusion and combined molding-rollingextrusion of aluminum alloys are developed.

Keywords: combined processes, metal treatment, molding, pressing.

\section{Инновационные совмещенные технологии при обработке металлов}

\section{С.Б. Сидельников,} Ю.В. Горохов, С.В. Беляев Сибирский федеральный университет Россия, 660041, Красноярск, пр. Свободный, 79

\begin{abstract}
Представлен обзор совмещённых технологий обработки металлов. Особое внимание уделено агрегатам, совмещающим литьё и непрерывное прессование. Экспериментально проверены теоретические зависимости между механическими свойствами пресс-изделий и параметрами процесса непрерывного литья-прессования. Спроектирована опытнопромышленная установка совмещенного литья-прессования алюминиевых и медных сплавов. Разработаны и исследованы способы совмещенной прокатки-прессования и совмещенного литья-прокатки-прессования алюминиевых сплавов.
\end{abstract}

Ключевые слова: совмещённые процессы, обработка металлов, литье, прессование.

(C) Siberian Federal University. All rights reserved

* Corresponding author E-mail address: sbs270359@yandex.ru 
Во второй половине XIX столетия в результате технической революции наметился резкий рост потребления металлоконструкций, который стимулировал создание ряда способов полунепрерывного и непрерывного литья металлов [1,2]. Полученные таким образом полуфабрикаты подвергались в основном последующей обработке давлением, в связи с чем возникла идея объединения этих операций в один непрерывный технологический процесс путем создания совмещенных технологий основных металлургических переделов в одном агрегате для производства требуемой продукции. В настоящее время созданы высокопроизводительные линии литейно-прокатных агрегатов (ЛПА) по производству сортового проката из черных и цветных металлов и сплавов. Однако использование ЛПА эффективно только в условиях массового производства, а при частых переходах с одного типоразмера профиля на другой при изготовлении небольших объемов применение ЛПА нерентабельно в связи с высокой стоимостью прокатного оборудования и затратами на его содержание и обслуживание. Особенно это относится к производству мелкосортной продукции, требующего наличия большого количества комплектов калиброванных валков. Здесь наиболее полно проявляются преимущества прессового производства. Так, последние достижения в области разработки процессов непрерывного прессования металлов и сплавов подтвердили эффективность замены в ЛПА прокатного стана на более универсальные установки непрерывного прессования или прокатки-прессования.

По этому принципу ведущими в этом направлении фирмами Babcock Wire Equipment и Holton Machinery LTD изготавливаются и тиражируются линии непрерывного прессования цветных металлов [3, 4] на базе установок Конформ. Высокое качество пресс-изделий и сравнительно низкая себестоимость их производства способствует повышенному спросу на линии Конформ, количество которых к настоящему времени перевалило за 1000. Дальнейшее совершенствование данного процесса связано прежде всего с проведением НИОКР, направленных на повышение его технико-экономических показателей. Ныне внимание не только зарубежных, но и отечественных металлургов направлено на совмещение операций литья и непрерывного прессования в одном агрегате, что позволит существенно снизить металлоемкость производственных линий, повысить их гибкость и степень автоматизации [5-7].

Первый такой агрегат был разработан с использованием машины Конформ, оснащенной элементами роторного кристаллизатора Д. Проперци. Производительность этих установок в основном зависит от скорости кристаллизации расплава и диаметра рабочего колеса установки. Так, при непрерывном литье-прессовании алюминиевых сплавов она составляет от 300 до 6000 кг/ч при диаметре колеса 300 и 1400 мм соответственно [8].

На рис. 1 приведена схема установки Кастэкс. Расплавленный металл с помощью устройства для регулирования расхода жидкого металла 4 поступает в канавку колеса 2 , имеющего интенсивное внутреннее охлаждение. В результате интенсивного охлаждения инструмента происходит непрерывное затвердевание металла в нижней части установки. Твердый металл достигает пресс-матрицы 7 и отпрессовывается по способу Конформ.

Способ прессования Кастэкс, при котором жидкий металл заливается в установку, является самым экономичным способом получения стандартной проволоки или профилей из всех других способов изготовления аналогичных изделий из твердого металла путем деформации [9]. Однако технических данных об этой установке, практических результатах эксплуатации в технической литературе не приводится, что объясняется, по-видимому, нежеланием авторов 


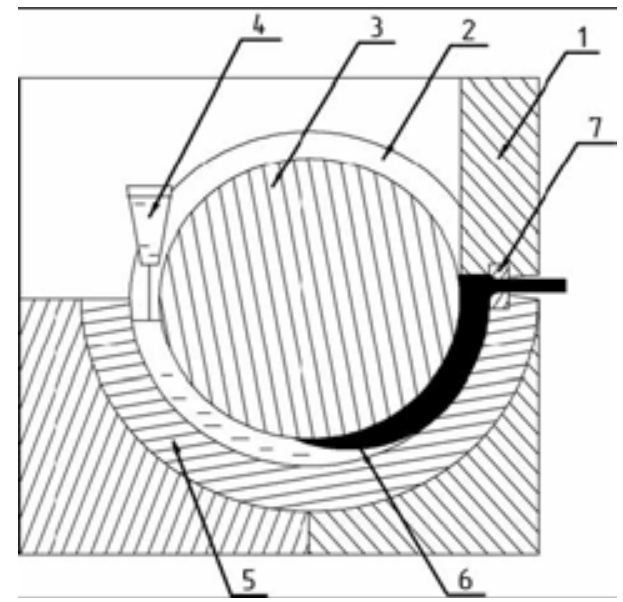

Рис. 1. Схема установки для непрерывного литья и прессования Кастэкс: 1 - разъемный корпус; 2 - кольцевая канавка; 3 - охлаждаемое колесо (ротор); 4 - устройство для регулирования расхода жидкого металла; 5 - кольцевая вставка; 6 - фронт кристаллизации; 7 - пресс-матрица

раскрывать путь преодоления определенных трудностей в осуществлении и поддержании стабильного, устойчивого процесса непрерывной кристаллизации жидкого металла и его прессования, во многом зависящего от эффективной работы системы непрерывной подачи расплавленного металла в канавку рабочего колеса. Она должна отвечать следующим требованиям:

- расплавленный металл не затвердевает в начальной фазе процесса;

- скорость перемещения расплавленного металла постоянна и соответствует скорости его затвердевания, определяемой интенсивностью теплоотвода от прессового инструмента;

- в потоке расплавленного металла исключены завихрения.

Использование базовой установки Конформ для непрерывной заливки в канавку рабочего колеса жидкого металла, его кристаллизация и прессование вызывают затруднения в соблюдении этих требований, в частности в стабилизации подачи металла в инструмент, вследствие «намораживания» жидкой фазы расплава при затвердевании на входную частью неподвижной кольцевой вставки. Устранение этого недостатка возможно при совмещении непрерывного прессования с непрерывным литьем металла на установке Конформ с вертикальной осью вращения колеса-кристаллизатора карусельного типа [10-12]. В результате исследований, проведенных сотрудниками кафедры «Обработка металлов давлением» ФГАОУ ВПО «Сибирский федеральный университет» под руководством Ю.В. Горохова, предложено устройство для совмещенного литья-прессования цветных металлов с вертикальной осью вращения колесакристаллизатора карусельного типа. На рис. 2 приведена схема установки совмещения непрерывного литья-прессования металла с помощью установки Конформ, выполненной на базе карусельного кристаллизатора [12].

Расплавленный металл из питателя (на чертеже не показан) поступает в дозатор 1 и далее заливается в кольцевую канавку 3, выполненную на верхней части диска кристаллизатора 2. При этом скорость заливки расплавленного металла в кольцевую канавку 3 осуществляется в строгом соответствии с частотой вращения кристаллизатора 2. За время движения до промежуточной неподвижной сегментной вставки 8 расплавленный металл охлаждается, кристалли-

$$
-187-
$$




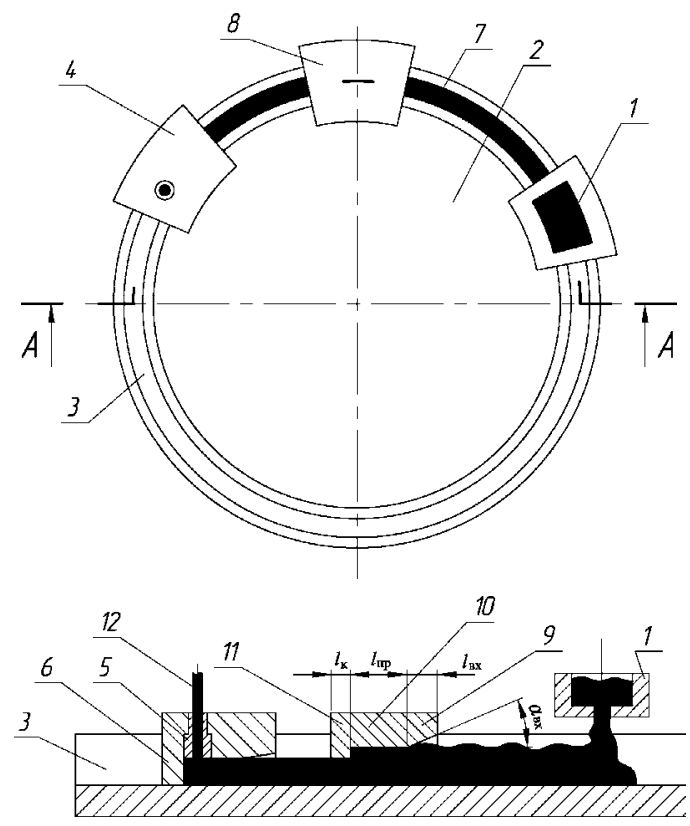

Рис. 2. Схема установки непрерывного литья и прессования методом Конформ: 1 - печь-миксер с дозатором; 2 - кристаллизатор; 3 - кольцевая канавка 3; 4 - основной неподвижный дугообразный сегмент; 5 - матрица; 6 - выступ; 7 - зона кристаллизации металла; 8 - промежуточная неподвижная сегментная вставка; 9, 10 - участки промежуточной неподвижной сегментной вставки; 11 - выступ, 12 - пресс-изделие

зируется и принимает форму поперечного сечения канавки 3. В промежуточной неподвижной сегментной вставке 8 на поверхности закристаллизовавшегося металла прорабатывается его наружный слой с литейными дефектами и увеличивается интенсивность контакта закристаллизовавшегося металла со стенками кольцевой канавки 3. Далее закристаллизовавшийся металл в кольцевой канавке 3 по ходу вращения кристаллизатора 2 достигает выступа 6 в основном неподвижном дугообразном сегменте 4, где под действием сил контактного трения между стенками кольцевой канавки 3 и закристаллизовавшимся металлом происходит его выдавливание в пресс-изделие 12 через рабочий канал вертикальной матрицы 5.

Разработанное устройство было реализовано в лабораторной установке (рис. 3), в состав которой входят: электродвигатель переменного тока 1 мощностью 3,0 кВт; редуктор 2 с передаточным отношением 10; кристаллизатор 5 , прикрепленный к корпусу 4 болтами; пресс-матрица 7; заливная воронка 8; соединительная муфта 3; дозатор 9. Все элементы прессового узла смонтированы на прочной сварной раме, обеспечивающей жесткость конструкции, предотвращая перекосы в соединительных муфтах и изгибы промежуточных валов в процессе литья - прессования металла.

На основе теории квазиравновесного двухфазного состояния были установлены температурные поля в переходной зоне твердожидкого расплава металла в канавке карусельного кристаллизатора для определения интенсивности и времени охлаждения слитка до заданной температуры прессования. Силовые параметры процесса определены методом баланса энергий, подводимых в деформационную зону и расходуемых в ней. Функциональная зависимость между механическими свойствами пресс-изделий и параметрами процесса непрерыв- 


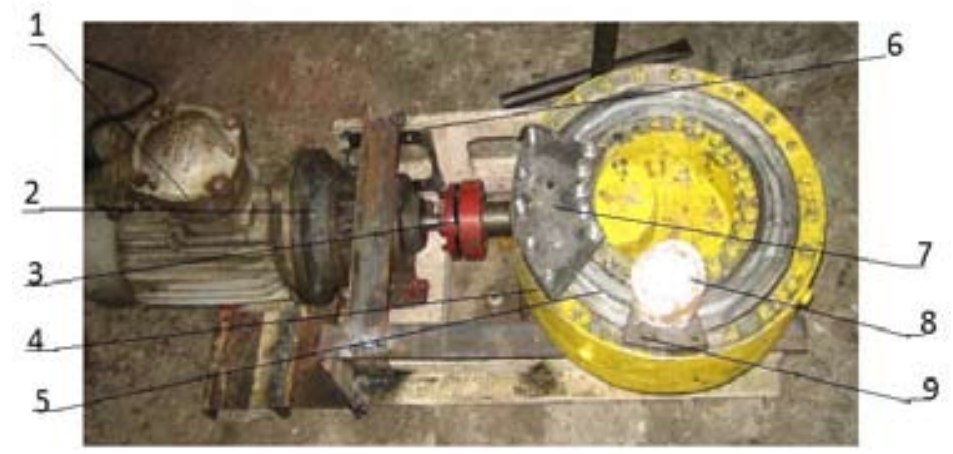

Рис. 3. Лабораторная установка непрерывного литья-прессования методом Конформ

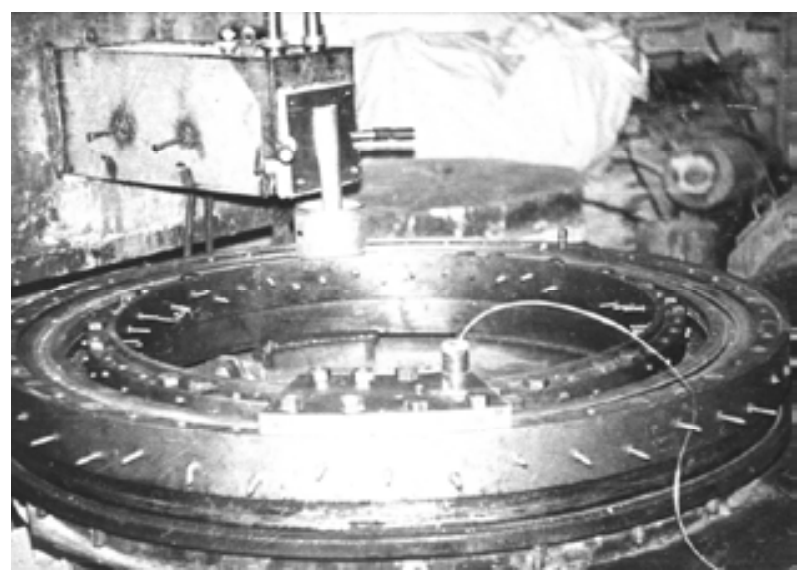

Рис. 4. Общий вид опытно-промышленной установки для совмещенного литья-прессования алюминиевых и медных сплавов

ного литья-прессования получена с применением элементов математического планирования экспериментов. Все это позволило определить такие важные технологические и конструктивные параметры, как длину башмака (контейнера), достаточную для осуществления непрерывного прессования затвердевшей части слитка; время кристаллизации расплава металла, поступившего в канавку движущегося колеса, и протяженность этого участка; место подачи расплава в канавку колеса в зависимости от заданных значений температуры и скорости прессования, интенсивности охлаждения рабочего инструмента, а также энергосиловые параметры установки.

Результаты экспериментальной проверки на лабораторной установке теоретических зависимостей доказали их достаточную надежность и целесообразность для практического применения и были использованы для технического и технологического проектирования опытнопромышленной установки совмещенного литья-прессования алюминиевых и медных сплавов (рис. 4).

Привод опытно-промышленной установки включает электродвигатель постоянного тока мощностью 90 кВт с максимальной частотой вращения 1000 об/мин и редукторы с общим пере-

$$
-189-
$$


даточным числом 320. Средний диаметр кольцевой канавки составляет 1200 мм, что при размере её поперечного сечения 40x40 мм обеспечивает производительность процесса непрерывного литья прессования латуни до 1,5 т в час. Для разливки расплавленного металла, поступающего из плавильной печи в литниковую коробку, применятся индукционный миксер ИЛКМ-2,5.

Опытно-промышленная установка совмещенного литья-прессования алюминиевых и медных сплавов, действующая по такой схеме, была нами спроектирована по заданию КаменскУральского завода ОЦМ и испытана в лаборатории кафедры ОМД Красноярского института цветных металлов и золота. Конструкция установки и принцип ее действия при изготовлении пресс-изделий из алюминиевых и медных сплавов описаны в монографии [5] и работе [6].

Таким образом, для отечественных металлургов создан инновационный комплекс технических и технологических решений в области непрерывного прессования методом Конформ и его совмещения с непрерывным литьем цветных металлов, внедрение которого позволит производить вполне конкурентоспособную продукцию на мировом рынке.

На этой же кафедре под руководством Н.Н. Довженко и С.Б. Сидельникова разработаны и исследованы способы совмещенной прокатки-прессования (СПП) и совмещенного литья-прокатки-прессования (СЛИПП) алюминиевых сплавов, которые по своим техникоэкономическим показателям могут составить конкуренцию способам Конформ и Кастэкс $[13,14]$. Экспериментальные исследования проводили на опытной установке СЛИПП, схема которой представлена рис. 5. В этом устройстве расплав заливается непосредственно в валкикристаллизаторы, кристаллизируется в виде заготовки прямоугольной формы, которая подвергается деформации при помощи тех же валков, а затем выдавливается через калибрующее отверстие матрицы.

Устройство включает в себя: печь миксер 1 с расплавом, валок 3 с ручьем и валок 4 с выступом, имеющие водоохлаждаемые полости 5 и образующие закрытый калибр, перекрытый на выходе матрицей 6. Игла 7 расположена в обойме 8 соосно каналу с помощью винта 10 и державки 11. По периметру иглы 7 в обойме 8 выполнены каналы 12 для подачи смазки. Соот-

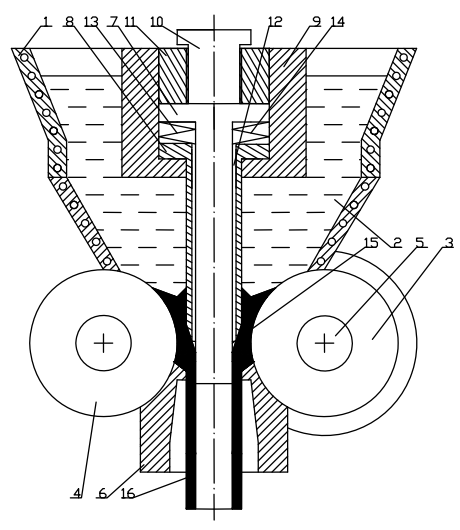

a)

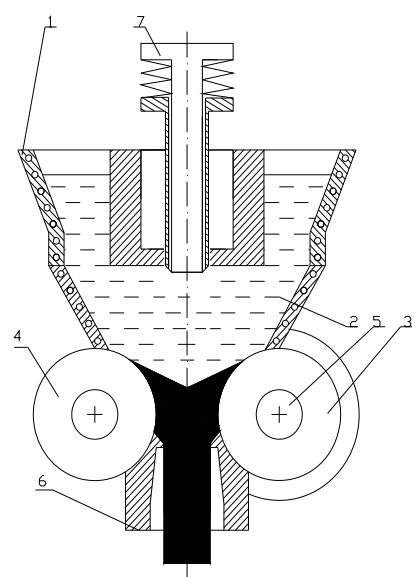

б)

Рис. 5. Устройство для бесслитковой прокатки-прессования полых (a) [15] и сплошных (б) пресс-изделий [16] 
ношение критической рабочей длины иглы 7 и диаметра валка с ручьем 3 составляет 0,05-0,35. Механизм отвода иглы включает винт 10 и пружины 13, 14, а игла на части своей длины снабжена выступами 15 , выполненными в поперечном сечении по форме каналов 12 . Клиновидные полости 16 выполнены в матрице 6 с возможностью их охлаждения.

Отличительной чертой данного устройства является то, что оно снабжено установленной соосно матрице длинномерной иглой с механизмом ее отвода, жестко закрепленной фиксатором и расположенной в обойме с каналами для подачи смазки, размещенными по периметру иглы выступами для запирания каналов. При этом в валках выполнены водоохлаждаемые полости.

\section{Список литературы}

[1] Ливанов В.А., Гибалуллин Р.М, Шипилов В.С. Непрерывное литье алюминиевых сплавов. М.: Металлургия, 1977. $168 \mathrm{c}$.

[2] Шатагин О.А., Сладкоштеев В.T. Непрерывное литье на горизонтальных машинах. М.: Металлургия, 1975. 184 с.

[3] Проспект фирмы Holton Machinery Ltd. (Великобритания), 1986. 29 с.

[4] Проспект фирмы Babcock Wire Equipment Ltd. (Великобритания), 1987. 27 с.

[5] Сергеев В.М., Горохов Ю.В., Соболев В.В., Нестеров Н.А. Непрерывное литье-прессование цветных металлов. М.: Металлургия, 1990. 85 с.

[6] Шеркунов В.Г., Сергеев В.М., Токарь В.П., Горохов Ю.В. Производство латунной заготовки методом совмещенного литья и непрерывного прессования. Свердловск - КаменскУральский, 1990. 30 с.

[7] Zhou T.G., Jiang Z.Y., Wen J.L.etc. // Materials Science and Engineering: A 2012. V. 8. P. 108114.

[8] Корнилов В.Н. // Технология легких сплавов. 1990. № 11. С. 60-62.

[9] B. Kellock B. // Mach. and Prod. 1982. (140). № 6. P. 58-59.

[10] Сергеев В.М., Горохов Ю.В., Шеркунов В.Г. и др. // Цветные металлы. 1988. № 12. С. 6567.

[11] Горохов Ю.В., Солопко И.В., Константинов И.Л. // Вестник МГТУ им. Г.И. Носова. 2009. № 3. C. 20-23.

[12] Пат. 111659 РФ, МПК В22D 11/06, В21C 23/00. Устройство для непрерывного литья и прессования металла методом конформ / Ю.В. Горохов, С.В. Беляев, В.Г. Шеркунов и др. / Опубл. 27.08.2012, Бюл. № 24.

[13] Сидельников С.Б. Автореф. дис. ... д-ра техн. наук. Красноярск, 2005.

[14] Сидельников С.Б., Довженко Н.Н., Галиев Р.И. и др. // Моделирование и развитие процессов обработки металлов давлением: Межвуз. сб. науч. тр. Магнитогорск: МГТУ, 2005. С. 33-42.

[15] Пат. 2200644 РФ, МПК В22D11/06, В21C23/08. Устройство для непрерывного литья и прессования полых профилей / Сидельников С.Б., Довженко Н.Н., Гришечкин А.И. и др. / Опубл. 20.03.2003, Бюл. № 8.6 c.

[16] Пат. 2100136 РФ, МКП В 22 D 11/06, В 21 С 23/00. Установка для непрерывного литья и прессования / Сидельников С.Б., Довженко Н.Н., Ешкин А.В. / Опубл. 27.12.1997, Бюл. № $36.6 \mathrm{c}$. 